\author{
Martina ZELEŇÁKOVÁ ${ }^{1}$ \\ Gabriela HUDÁKOVÁ ${ }^{2}$
}

\title{
THE NECESSITY OF HYDROGEOLOGICAL SURVEY IN INFILTRATION SYSTEMS DESIGN
}

\begin{abstract}
With the development of construction in large cities and their surroundings there is still more to tackle with congestion of sewer network. There are many alternatives that can reduce the risk of flooding, regulate the quantity and quality of groundwater. Most of these alternatives are proposed as a theoretical conversion according to standards. Infiltration practices represent one of the best methods of rainwater management which may effectively reduce load of interflow network. Rainwater management should be considered to be the sustainable strategy for reconstruction of rural and urban settlement from the aspect of environment, management and social criteria. Our aim in the paper is to compare the theoretical calculations with practice. We would like to stress that the hydrogeological survey is inevitable condition before design of any infiltration systems.
\end{abstract}

Keywords: rainwater, infiltration, percolation, rain gauge, rainfall-drainage process, surface runoff

\section{Introduction}

Infiltration can occur naturally following precipitation, or can be induced artificially through structural modifications in the ground surface. Some water that infiltrates will remain in the soil layer, where it will gradually move vertically and horizontally through the soil and subsurface material. Eventually, it might enter a stream by seepage into the stream bank. Some of the water may continue to move deeper (percolate), recharging the local groundwater aquifer. A dry soil has a defined capacity for infiltrating water.

The capacity can be expressed as a depth of water that can be infiltrated per unit time, such as inches per hour. If rainfall supplies water at a rate that

\footnotetext{
${ }^{1}$ Corresponding author: Technical University of Košice, Faculty of Civil Engineering, Institute of Environmental Engineering, Vysokoškolská 4, 04200 Košice, Slovak Republic, tel.+421 55602 4270, e-mail: martina.zelenakova@ tuke.sk

2 Technical University of Košice, Faculty of Civil Engineering, Institute of Environmental Engineering, Vysokoškolská 4, $042 \quad 00$ Košice, Slovak Republic, e-mail: gabriela.hudakovaa@gmail.com
} 
is greater than the infiltration capacity, water will infiltrate at the capacity rate, with the excess either being ponded, moved as surface runoff, or evaporated. If rainfall supplies water at a rate less than the infiltration capacity, all of the incoming water volume will infiltrate. In both cases, as water infiltrates into the soil, the capacity to infiltrate more water decreases and approaches a minimum capacity. When the supply rate is equal to or greater than the capacity to infiltrate, the minimum capacity will be approached more quickly than when the supply rate is much less than the infiltration capacity. The emerging goal of urban rain water management is to achieve effective control of pollutants in rain water runoff and reduce the volume and rate of runoff to control downstream impacts from flooding and stream-channel erosion [1].

\subsection{Hydrogeological characteristics}

Important prerequisites for the percolation of precipitation water is the sufficient permeability of the soil as well as of the loose and solid rock in the subsoil. Attention is to be paid that the surface, possibly artificially applied, has a lower permeability than the subsoil and thus represents the relevant $k_{\mathrm{f}}$ - value. With $k_{\mathrm{f}}$-values of less than $1.10^{-6}$ drainage exclusively through percolation with temporary storage is not guaranteed from the outset, so that a supplementary possibility for discharge is to be planned.

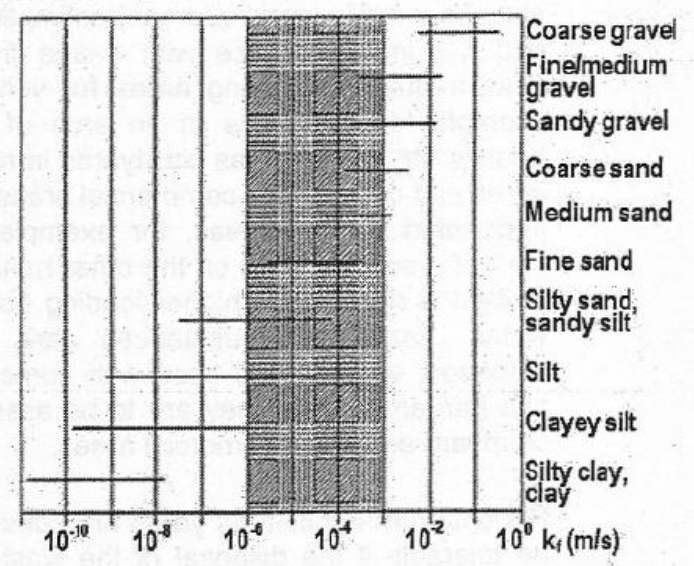

Fig. 1. Water permeability coefficients of loose rock and percolation range for technical drainage

The permeability of the loose rock depends predominantly on the size and distribution of its particles and compactness; with soils also decisively on soil structure and the water temperature, and is given through the permeability coefficient $\left(k_{\mathrm{f}}\right.$ - value). With loose rock it varies in general between $1.10^{-2}$ and $1.10^{-10} \mathrm{~m} / \mathrm{s}$. The $\mathrm{k}_{\mathrm{f}}$ - values apply for flow processes in the water saturated zone. Decisive for the spreading of water content substances into the unsaturated zone 
and for the protective effect of the groundwater cover is not the $k_{\mathrm{f}}$ - value determined for the saturated zone, but rather the smaller $k_{\text {f,imp }}$ - value in the unsaturated zone. The percolation, range relevant for technical drainage lies around a $k_{\mathrm{f}}$ range from $1.10^{-3}$ to $1.10^{-6} \mathrm{~m} / \mathrm{s}$ (Figure 1) [2].

\section{Percolation measurements and permeability coefficients}

When planning a rain water drainage system it is necessary to determine the volume of rainfall, depending on the duration of rainfall and its intensity. For practical use there is available statistical data of the rain intensity from period of about ten years. There are large discrepancies between the intensity of rainfall for the drainage design of buildings and intensity of rainfall values for the dimensions of the public sewer system.

\subsection{Percolation measurements in Košice}

At the beginning of the year 2011 measurement devices discussed in the following were placed in percolation shaft, which is located in area of campus of Technical University in Košice (fig. 2). The measuring channel is placed there with the aim of monitoring quantity and quality of rainwater. Unit M4016 with modem with UZV sensor is used for subtraction of values. The final results from this unit are on-line available as values of the height of water level $[\mathrm{mm}]$ in the shaft, flow rate $[1 / \mathrm{s}]$ of incoming rain water from roof of the building, flow rate $\left[\mathrm{m}^{3}\right]$, temperature of rain water $\left[{ }^{\circ} \mathrm{C}\right]$ and $\mathrm{pH}$ values. The values of precipitation are measured by rain gauge which is located on the roof of the building of Library of the University in Košice. Rain gauge is located about 300 $\mathrm{m}$ from infiltration shaft also in the area of University campus. All measured values will be used for the design of drainage and infiltration system in the area.

In the percolation shaft (fig. 3.) devices measure mentioned parameters amount of runoff from roof (quantity) and amount of water in the shaft (in the measuring channel and the height in the shaft) and also quality of water (which is not the objective of this paper). Also the amount of precipitation is measured in the same time at the roof of University library. If we want to use this data together, compare them and conclude some relations, all of these mechanisms should be located very close to each other and the timing must be synchronized. 


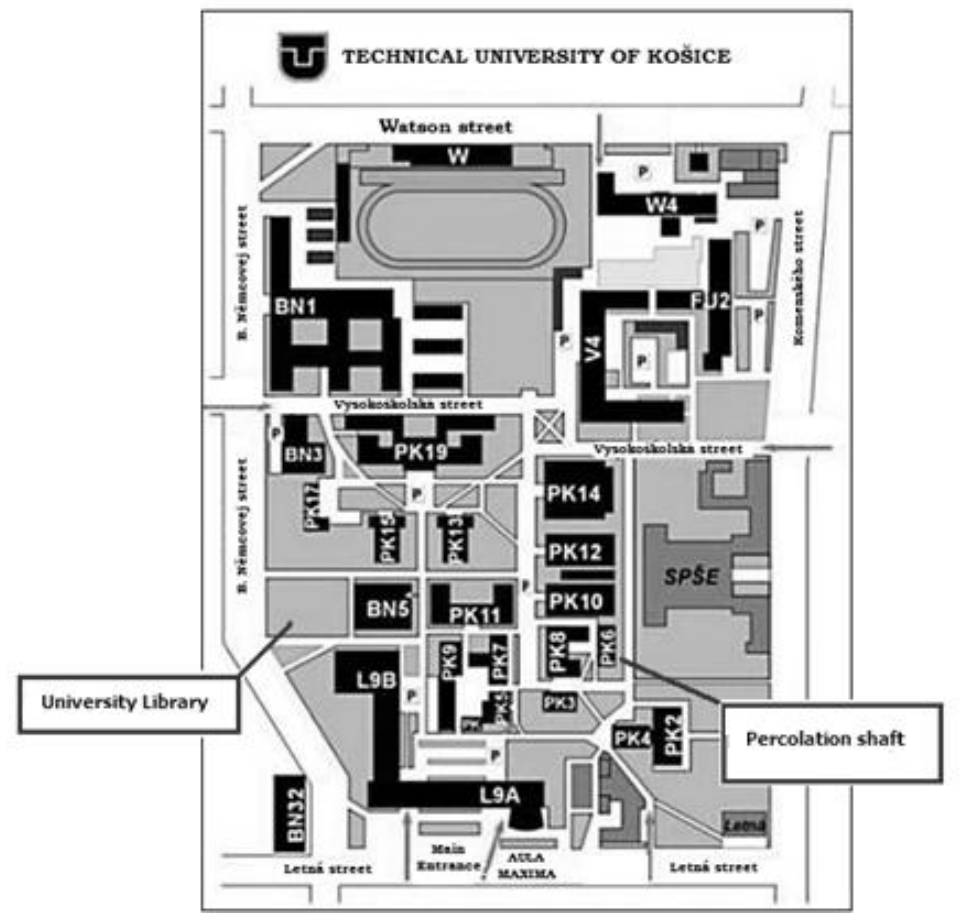

Fig. 2.Location of measuring devices

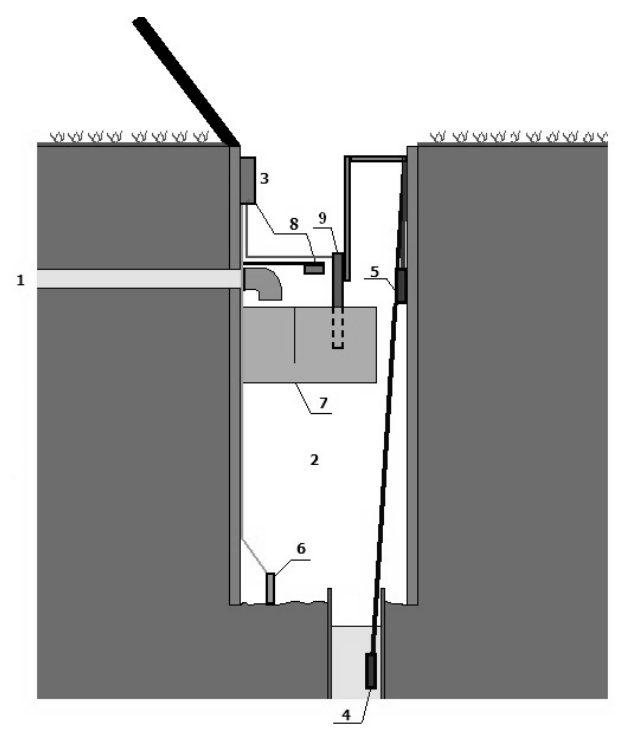

Fig. 3. Percolation shaft: 1-supply of rainwater from roof; 2-percolation shaft; 3- data telemetric unit M4016; 4-levelogger; 5-barologger; 6- pressure sensor; 7-measuring channel; 8- UZV - sensor; 9-multiparameter probe 


\subsection{Percolation measurements in Prešov}

This chapter deals with percolation measurements in Šarišské Lúky near Prešov where rainwater drainage from road bridge after its reconstruction was performed and subsequent research on rainwater infiltration is done. The infiltration gallery was designed by theoretical calculation. The accuracy of the theoretical calculation will be defined on a real attribute basis from detected measurements.

Figure 4 shows the deployments of objects in the area in which measuring equipment for research are located. Rainwater from the bridge is drained to a filter shaft. The filter shaft, infiltration gallery and inspection shaft are interconnected. Rainwater from the bridge runs into filter shaft (1), which serves for capture and sedimentation of coarse and fine impurities. The rainwater subsequently flows into the infiltration gallery (2), where the water is filtered. A flow meter is located in the filter shaft, which record incoming rainwater in $1 / \mathrm{s}$. The water level in the infiltration gallery can be monitored by means of the floatgauge which is located in inspection shaft (3). Near this infiltration gallery is located rain-guage (4).
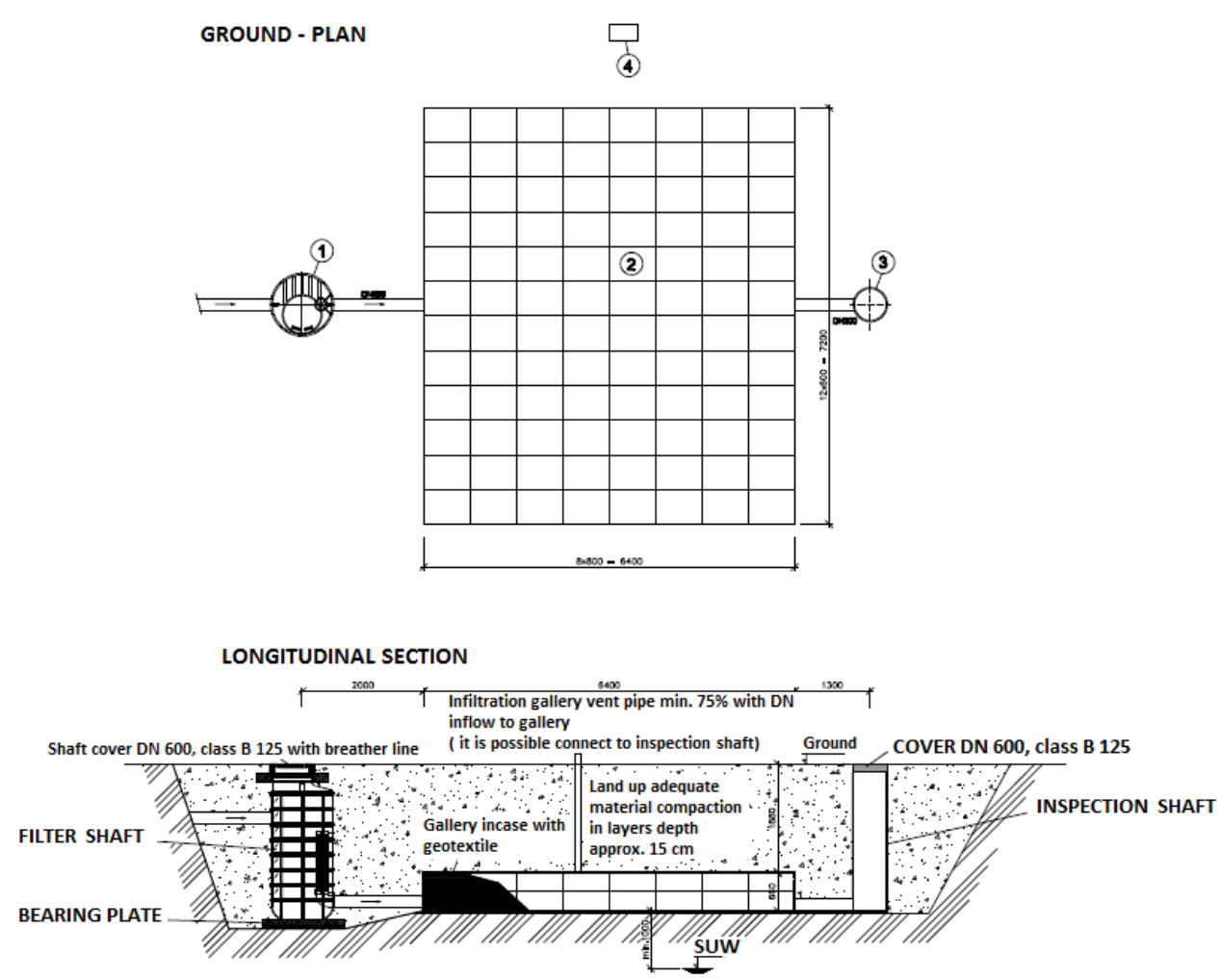

Fig. 4 .Object placement in the area 


\subsection{Permeability coefficients}

For the calculation of the percolation rate Darcy's law is applied as the hydraulic basis for the percolation calculation [2]:

$$
v_{f}=k_{f} . . I_{h y}
$$

where: $v_{\mathrm{f}}$ - filter rate of the saturated zone in $\mathrm{m} / \mathrm{s}$;

$k_{\mathrm{f}}-$ coefficient of hydraulic conductivity of the saturated zone in $\mathrm{m} / \mathrm{s}$;

$I_{\text {hy }}-$ hydraulic gradient in $\mathrm{m} / \mathrm{m}$.

The coefficient of hydraulic conductivity of non-water-saturated soil is smaller than for water-saturated soil. Simplified, the coefficient of unsaturated hydraulic conductivity is assumed to be $\mathrm{k}_{\mathrm{f}} / 2$.

With percolation facilities with small impoundage heights the hydraulic gradient will only be slightly different to 1 . Therefore, as an approximation, $I_{\mathrm{hy}}=$ 1 can be applied. Thus, as a rule, the percolation rate is given as [4]:

$$
Q_{P}=v_{f} . . A_{P}=k_{f} / 2 . A_{p}
$$

where: $Q_{\mathrm{P}}-$ percolation rate in $\mathrm{m}^{3} / \mathrm{s}$;

$A_{\mathrm{P}}$ - percolation area in $\mathrm{m}^{2}$.

Then

$$
k_{f}=2 \cdot Q_{p} / A_{p}
$$

The percolation area $A_{\mathrm{p}}$ results depend on the impoundage level. With above-ground percolation facilities the horizontal projection of the surface of the water table can used in simplified form as the basis. The required storage volume $(V)$ represents an essential dimensioning parameter and can be calculated from the equation:

$$
V=Q_{p} \cdot T
$$

where: $T$ - time of rain duration in seconds.

Then

$$
Q_{p} \cdot=V / A_{p}
$$




\section{Results}

The aim of the research was to calculate the hydraulic conductivity/permeability coefficients and compare them with the values from laboratory measurements. The hydraulic conductivity coefficients were calculated from equation (3). We considered a few events in Košice and in Prešov according Tables 1 and 2. The percolation area of infiltration shaft is $0,785 \mathrm{~m}^{2}$.

The results from the calculation of coefficients of hydraulic conductivity are presented in Table 1.

Table 1: Calculated coefficients of hydraulic conductivity in Košice

\begin{tabular}{|c|c|c|c|c|c|c|c|}
\hline Date & $\begin{array}{c}\text { Time } \\
\text { from }\end{array}$ & $\begin{array}{c}\text { Time } \\
\text { to }\end{array}$ & $\begin{array}{c}\boldsymbol{V} \\
{\left[\mathbf{m}^{3}\right]}\end{array}$ & $\begin{array}{c}\boldsymbol{T} \\
{[\mathbf{s}]}\end{array}$ & $\begin{array}{c}\boldsymbol{Q}_{\mathbf{p}} \\
{\left[\mathbf{m}^{\mathbf{3}}\right]}\end{array}$ & $\boldsymbol{A}_{\mathbf{p}}\left[\mathbf{m}^{2}\right]$ & $\begin{array}{c}\boldsymbol{k}_{\mathbf{f}} \\
{\left[\mathbf{m}^{\mathbf{2}}\right]}\end{array}$ \\
\hline $\begin{array}{c}5.11 .2013 \\
6.11 .2013\end{array}$ & $13: 36$ & $1: 00$ & 2,03 & 41040 & $4,95.10^{-5}$ & 0,785 & $1,26.10^{-4}$ \\
\hline $\begin{array}{c}9.11 .2013 \\
10.11 .2013\end{array}$ & $20: 02$ & $5: 08$ & 0,77 & 32760 & $2,35.10^{-5}$ & 0,785 & $5,99.10^{-5}$ \\
\hline 19.3 .2013 & $2: 03$ & $11: 18$ & 0,17 & 33300 & $5,11.10^{-6}$ & 0,785 & $1,30.10^{-5}$ \\
\hline $\begin{array}{l}15.1 .2013 \\
16.1 .2013\end{array}$ & $00: 38$ & $5: 38$ & 0,31 & 104400 & $2,97.10^{-6}$ & 0,785 & $7,56.10^{-6}$ \\
\hline $\begin{array}{l}19.9 .2012 \\
20.9 .2012\end{array}$ & $19: 21$ & $15: 05$ & 1,25 & 71040 & $1,76.10^{-5}$ & 0,785 & $4,48.10^{-5}$ \\
\hline 21.7 .2012 & $0: 03$ & $11: 02$ & 2,31 & 39540 & $5,84.10^{-5}$ & 0,785 & $1,49.10^{-4}$ \\
\hline $\begin{array}{l}16.5 .2012 \\
17.5 .2012\end{array}$ & $10: 29$ & $1: 03$ & 0,3 & 52440 & $5,72.10^{-6}$ & 0,785 & $1,46.10^{-5}$ \\
\hline $\begin{array}{l}1.11 .2012 \\
5.11 .2012\end{array}$ & $13: 20$ & $14: 29$ & 1,51 & 349740 & $4,32.10^{-6}$ & 0,785 & $1,10.10^{-5}$ \\
\hline $\begin{array}{l}16.12 .2011 \\
17.12 .2011\end{array}$ & $17: 08$ & $2: 37$ & 0,72 & 34140 & $2,11.10^{-5}$ & 0,785 & $5,37.10^{-5}$ \\
\hline 17.12 .2011 & $6: 16$ & $15: 32$ & 1,16 & 33360 & $3,47.10^{-5}$ & 0,785 & $8,86.10^{-5}$ \\
\hline
\end{tabular}

The result from laboratory measurements is that the hydraulic conductivity coefficient in the area of interest is $1,58.10^{-3}$ in Košice. That is a little higher than the ones from the field measurements. In subsequent research it will be necessary to monitor more rain events and also calculate the uncertainty factor.

The second place on measurements of rainfall and calculate hydraulic conductivity coefficients was in Prešov.

The storage volume is monitored in the filter shaft. The percolation area of the infiltration gallery is $46,08 \mathrm{~m}^{2}$. Its surface is rectanglular. The results from the calculation of coefficients of hydraulic conductivity are presented in Table 2. 
Table 2: Calculated coefficients of hydraulic conductivity in Prešov

\begin{tabular}{|c|c|c|c|c|c|c|c|}
\hline Date & $\begin{array}{c}\text { Time } \\
\text { from }\end{array}$ & $\begin{array}{c}\text { Time } \\
\text { to }\end{array}$ & $\begin{array}{c}\boldsymbol{V} \\
{\left[\mathbf{m}^{\mathbf{3}}\right]}\end{array}$ & $\begin{array}{c}\boldsymbol{T} \\
{[\mathbf{s}]}\end{array}$ & $\begin{array}{c}\boldsymbol{Q}_{\mathbf{p}} \\
{\left[\mathbf{m}^{\mathbf{3}}\right]}\end{array}$ & $\begin{array}{c}\boldsymbol{A}_{\mathbf{p}} \\
{\left[\mathbf{m}^{2}\right]}\end{array}$ & $\begin{array}{c}\boldsymbol{k}_{\mathbf{f}} \\
{\left[\mathbf{m}^{2}\right]}\end{array}$ \\
\hline $\begin{array}{c}2.4 .2013 \\
4.4 .2013\end{array}$ & $22: 52$ & $3: 46$ & 1,72 & 104040 & $1,65.10^{-5}$ & 46,08 & $7,18.10^{-7}$ \\
\hline $\begin{array}{c}1.2 .2013 \\
28.2 .2013\end{array}$ & $1: 48$ & $22: 35$ & 6,99 & 2407620 & $2,90.10^{-5}$ & 46,08 & $1,26.10^{-7}$ \\
\hline $\begin{array}{c}30.1 .2013 \\
31.1 .2013\end{array}$ & $3: 00$ & $23: 51$ & 1,27 & 161460 & $7,87.10^{-6}$ & 46,98 & $3,41.10^{-7}$ \\
\hline $\begin{array}{c}15.1 .2013 \\
16.1 .2013\end{array}$ & $11: 10$ & $14: 51$ & 3,15 & 99660 & $3,16.10^{-5}$ & 46,08 & $1,37.10^{-6}$ \\
\hline $\begin{array}{c}15.12 .2012 \\
19.12 .2012\end{array}$ & $18: 56$ & $16: 30$ & 1,4 & 335820 & $4,17.10^{6}$ & 46,08 & $1,81.10^{-7}$ \\
\hline 1.11 .2012 & $10: 40$ & $23: 02$ & 0,12 & 44520 & $2,71.10^{-6}$ & 46,08 & $1,18.10^{-7}$ \\
\hline $\begin{array}{l}19.9 .2012 \\
20.9 .2012\end{array}$ & $19: 49$ & $15: 51$ & 3,07 & 72120 & $4,26.10^{-6}$ & 46,08 & $1,85.10^{-6}$ \\
\hline
\end{tabular}

The result from laboratory measurements is that the hydraulic conductivity coefficient in the area of interest is $4,84 \cdot 10^{-7}$. That is a little higher that the ones from the field measurements. In subsequent research it will be necessary to monitor more rain events and also calculate the uncertainty factor.

\section{Conclusion}

Infiltration control represents one of the best methods of rainwater management which may effectively reduce the load on the sewerage network.

Rainwater management should be considered as a sustainable strategy for reconstruction of rural and urban settlements from the aspects of environmental management and social criteria [4]. There are many possibilities which can reduce the risk of flooding and regulate the quantity and quality of ground water. Most of these possibilities are proposed only by theoretical calculation based on norms. Our aim is to compare theoretical calculations with results from practice.

Best management practices reflect the natural process of infiltration that can be found in non-urban basins. Infiltration control belongs among the best management practices that are able to effectively reduce the overloading of sewerage systems by rainwater drainage. If local conditions allow, part of the urban runoff must be controlled by infiltration.

The new challenge for management of rainwater and groundwater requires a fundamental change in the way we think about this issue. Rainwater should be regarded from the point of view of alternative, sustainable strategies and as re- 
habilitation of rural and urban settlements in the context of environmental, economic and social criteria.

\section{Acknowledgement}

The Centre was supported by the Slovak Research and Development Agency under the contract No. SUSPP-0007-09

\section{References}

[1] General Information for Infiltration Practices: Iowa Stormwater Management (ISM) Manual, 2008.

[2] DWA - A138 Planung, Bau und Betrieb von Anlagen zur Versickerung von Niederschlagswasser, 2005.

[3] Zeleňáková, M., Rejdovjanová, G.: Drainage possibilities and its alternations (in Slovak). Proceedings of LAWA conference Košice: Elsewa, 2010.

[4] Vranayová, Z., Karelová, Z., Očipová, D.: Precipitation Monitoring Methodology at the Campus of Technical University of Košice. In: Selected Scientific Papers. Journal of Civil Engineering. Vol. 6/2, 2011.

\section{THE NECESSITY OF HYDROGEOLOGICAL SURVEY IN INFILTRATION SYSTEMS DESIGN}

\section{S u m m a r y}

Nowadays, reinforced surface drainage represents one of the current issues in rainwater management. Comparing situation of reinforced and green surfaces in the past and present, it is clear that there is a reduction of the green surfaces. As a result of this reduction there is decrease in effect of evapotranspiration, also in percolation of waters from surface runoff to soil and to under-surface water layers and simultaneously there is an increase of surface runoff from reinforced surfaces. Moreover, there are changes in subsoil because of the reduction of waters from surface runoff to under-surface water layers. These changes cause disruption in thousandyear long natural hydrological cycle of groundwater which subsequently influences many other factors such as change in subsoil and water management. Change of hydrological cycle causes reduction of groundwater levels as well as levels of natural subsurface reservoirs of drinking water. This article deals the necessity of hydrogeological survey in infiltration systems design with runoff from building roof in the area of campus of Technical university in Kosice and road drainage of Prešov suburb where research of rainwater infiltration.

Keywords: rainwater, infiltration, percolation, rain gauge, rainfall-drainage process, surface runoff

DOI:10.7862/rb.2014.68

Przestano do redakcji: lipiec $2014 \mathrm{r}$.

Przyjęto do druku: wrzesień 2014 r. 